\title{
The Analysis of Certain Differences in Motor Skills of Sedentary Male Children in the 9-14 Age Group Based on the Biological Maturity
}

\author{
Işık Bayraktar ${ }^{1}$, Nigar Yaman ${ }^{2, *}$, Erdal Zorba $^{3}$, Metin Yaman $^{3}$, Mehmet Günay $^{3}$ \\ ${ }^{1}$ Turkey General Directory of Sport, Turkey \\ ${ }^{2}$ School of Physical Education and Sport, Bartin University, Turkey \\ ${ }^{3}$ School of Physical Education and Sport, Gazi University, Turkey
}

Copyright $\bigcirc 2016$ by authors, all rights reserved. Authors agree that this article remains permanently open access under the terms of the Creative Commons Attribution License 4.0 International License

\begin{abstract}
The aim of this study consists of the analysis of certain differences in motor skills of male children who are sedentary and in the age group of $9-14$, in relation to the biological maturity. 522 sedentary male children from various parts of Turkey participated in this study. Body height and body weight measurements were taken from the participants in order to determine their body mass indexes while finger grip strength, hand grip strength, standing long jump test, med ball throwing test, flexibility test (sit-reach), active jump test, anaerobic power test, 20 meter sprint, pro-agility test and 20 meter shuttle run tests were applied in order to determine certain motor skill levels of the participants. The motor skill levels of the participants were noticed to show significant differences generally based on the age groups $(p<0.05)$. The biological maturity levels of the participants were determined to be a factor which significantly affected the performances of the participants in aerobic durability, right and left hand grip strength, right and left finger grip strength, flexibility, med ball throwing, standing long jump and sargent jump $(p<0.05)$. On the other hand, the findings regarding the speed performances were observed to show conflicting results, therefore biological maturity was found not to be a determinant over the 20 meter speed performance. As a result, certain motor skill differences in relation with biological maturity were observed in the sedentary male students of the 9-14 age group. Therefore, it can be stated that in order to reach reliable results, considering the biological maturity levels of the students along with the obtained test scores in sports skills qualification tests can be beneficial.
\end{abstract}

Keywords Psychomotor Development, Biological Maturity, Chronological Age, Adolescent, Skill Qualification, Motor Development, Motor Skill

\section{Introduction}

Growth and development are part of a process in the human life that begins prior to birth and continues until death [1]. Through this process, physical growth also shows a significant increase, especially within the first few periods after birth [2]. The increments in physical growth occur in body weight and physical growth [3]. The most distinct indicator of children's health is the accruing of growth and development without disruption. At this point determining the pace of growth and development of the children is very important. Chronological and carpal age have an important place in the pace of growth and evaluation of the periods in question. The pace of development of the child can be stated as being fast, provided that the carpal age of the child is great, even if the chronological age of the child is young. However if the chronological age of the child is advanced, and the carpal age is very young, it can be inferred that the physical development of the child is progressing very slowly [4].

Growth is described as the increment in body size due to the cells' multiplication [5]. In addition to the increment in cells and body mass during growth, the process of growth begins with conception and continues through the end of the adolescent period. Beginning with the genetic constitution, there is a list of factors that affect growth [6].

Although growth and development are part of a process which begins with impregnation and continues through the end of puberty, the pace shows acceleration and deceleration in certain periods. The growth occurs at a relatively stable and slow pace from the ages of 4 to 9-10, and accelerates while approaching puberty [7]. Therefore, the pace of growth is not always the same and it is a notion which can be observed from the outside [8].

Observation of the physical and biological maturity level of the child is very important in terms of acquiring knowledge related to the level and health of development [9]. 
Generally biological maturity and anthropometric growth levels are known to be factors that are related to inheritance [10].

The notion of motor skill is a term used in a variety of fields such as neurology, medical, psychology and sports sciences. Motor skill is a far-reaching field which also includes the notion of movement. In general, motor skill is the whole of processes, including the learning of the flow, act, yield, rhythm and element of the movement along with error correction. Motor skill, according to another description, is the movement group that is learned at an optimal rate through the effect of experience and learning. In this aspect, basic motions such as walking, running, jumping and capriole are motor skills that are developed within the first few periods of life [11].

Motor skills are actualized through a complicated mechanism which is called motor learning. Motor learning means the change occurring in the motor performance through experience and learning of the movement. In order to mention motor learning, not only is an improvement in performance required, but also this improvement needs to happen through learning. Motor development which develops in children in parallel with motor learning, occurs depending on the physical growth and the development of the cortex and central nervous system. Therefore, limiting the development observed in motor skills to a certain age is not the case [1].

Paying attention to physiological capacity measurements alongside the elements of physical and motoric performances is very important in directing young children to sports with the help of talent tests. Because the ability to achieve high levels of success of the children who are led to sports branches through the talent tests is closely related to their physiological structure and capacity besides their physical and motoric features [12]

The ages and certain physical features of the children are known to have a great importance for the sports branches to which they will be directed. However, although studies which analyze the relation between the chronological age and motor development of the children were found to exist within the literature, studies which deal with the effects of biological maturity over the motor skills were insufficient. In this regard the aim of this study is to examine the effects of biological maturity over motor skills in the talent selection process of the children.

\section{Method}

The population of the study consists of male Turkish children whose ages vary through 9-14 $(n=3.881 .632)$ (TUIK, 2013). The sample group however included 9-14 year old male $(n=522)$ children who do not perform sport activities, and live in various parts of Turkey (Ankara, Adiyaman, Bolu, Hatay, Karabuk, Mugla, Sakarya and Samsun). At least 50 voluntary participants for every age group were included in the measurements.

The children were informed about the tests at least a day before the measurements. Body Height, body mass, right-left hand grip strength, right-left finger grip strength, flexibility, active countermovement jump, standing long jump, med ball throw, 20 meter speed run, pro-agility and 20 meter shuttle run tests and measurements were performed during the testing process, in the respective order. The participants were fully rested between the tests in the measurement process.

Kruskall Wallis H-test was applied in order to identify the differences of the biological maturity levels of the participants with certain motoric features. The z-scores were calculated in order to rate the calculated maturity coefficient. The values which were calculated for the z-scores were rated as "late" if the value was greater than 1, "early" in cases where the value was smaller than -1 and "medium" maturity level when the value did not fit any of these two criteria. The level of significance was taken as 0.05 in the SPSS 17 packaged software which was used for statistical analyses.

\section{Findings}

Table 1. The mean and standard deviation values of the participants in terms of age, body height, body weight and body mass index.

\begin{tabular}{|c|c|c|c|}
\hline \multirow{2}{*}{ Age (year) } & $\begin{array}{l}\text { BodyHeight } \\
\text { (cm) }\end{array}$ & $\begin{array}{c}\text { Body Weight } \\
(\mathrm{kg})\end{array}$ & $\begin{array}{c}\text { Bodymassindex } \\
\left(\mathrm{kg} / \mathrm{m}^{2}\right)\end{array}$ \\
\hline & $\hat{0}$ & đ & a \\
\hline$(\hat{\delta}=57)$ & $130.9 \pm 7.0$ & $28.9 \pm 5.0$ & $16.7 \pm 1.7$ \\
\hline $10(\hat{\jmath}=64)$ & $136.2 \pm 10.3$ & $33.1 \pm 9.3$ & $17.7 \pm 3.2$ \\
\hline $11\left(\partial^{\lambda}=112\right)$ & $140.4 \pm 8.6$ & $37.8 \pm 10.4$ & $19.0 \pm 4.1$ \\
\hline $12\left(\delta^{\lambda}=123\right)$ & $145.2 \pm 8.8$ & $39.7 \pm 9.8$ & $18.6 \pm 3.3$ \\
\hline $13(\hat{\jmath}=95)$ & $152.9 \pm 9.4$ & $45.2 \pm 10.6$ & $19.2 \pm 3.0$ \\
\hline $14(\hat{\jmath}=71)$ & $156.8 \pm 8.6$ & $48.9 \pm 10.5$ & $19.7 \pm 3.0$ \\
\hline $\operatorname{Total}(\widehat{\jmath}=522)$ & $144.5 \pm 12.0$ & $39.6 \pm 11.4$ & $18.6 \pm 3.4$ \\
\hline
\end{tabular}

Upon the examination of the Table 1, the body height and body weight values of the participants were observed to increase depending on the increase of age, in a linear manner. 


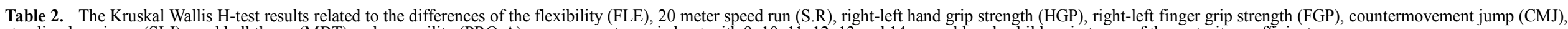
standing long jump (SLJ), med ball throw (MBT) and pro-agility (PRO-A) measurements carried out with 9,10,11,12,13 and 14 year old male children in terms of the maturity coefficients.

\begin{tabular}{|c|c|c|c|c|c|c|c|c|c|c|c|c|}
\hline \multicolumn{2}{|c|}{ Maturity Coefficient } & FLE (cm) & $\begin{array}{c}\text { 20.m SR } \\
\text { (sn) }\end{array}$ & $\begin{array}{c}20 \text { M. SR } \\
\text { (adet) }\end{array}$ & $\begin{array}{c}\text { HGP RIGHT } \\
(\mathrm{kg})\end{array}$ & $\begin{array}{l}\text { HGP LEFT } \\
\text { (kg) }\end{array}$ & $\begin{array}{c}\text { FGP LEFT } \\
\text { (kg) }\end{array}$ & $\begin{array}{c}\text { FGP RIGHT } \\
(\mathrm{kg})\end{array}$ & CMJ (cm) & SLJ (cm) & MBT (cm) & PRO-A (sn) \\
\hline \multicolumn{13}{|c|}{9 YEAR AGE GROUP } \\
\hline \multirow{2}{*}{ Early(6) } & $\mathrm{X}$ mean & 15.55 & 4.35 & 43.00 & 15.20 & 15.75 & 4.50 & 4.17 & 20.78 & 122.33 & 355.83 & 7.19 \\
\hline & SS & 6.35 & 0.09 & 6.00 & 3.53 & 5.26 & 0.55 & 0.75 & 3.24 & 17.74 & 66.06 & 0.81 \\
\hline \multirow{2}{*}{ Medium (35) } & $\mathrm{X}$ mean & 19.61 & 4.47 & 39.40 & 12.76 & 12.75 & 4.00 & 3.71 & 17.66 & 114.74 & 299.06 & 7.37 \\
\hline & SS & 7.17 & 0.39 & 6.72 & 3.16 & 2.65 & 0.84 & 0.83 & 4.16 & 19.10 & 93.73 & 0.65 \\
\hline \multirow{2}{*}{ Late (16) } & $\mathrm{X}$ mean & 18.65 & 4.60 & 40.00 & 11.16 & 10.51 & 3.50 & 3.19 & 16.96 & 113.00 & 271.06 & 7.43 \\
\hline & SS & 3.26 & 0.29 & 0.00 & 3.08 & 2.74 & 0.82 & 0.75 & 3.36 & 16.64 & 91.80 & 0.87 \\
\hline \multirow{5}{*}{ Total(57) } & $\mathrm{X}$ mean & 18.92 & 4.50 & 39.95 & 12.57 & 12.44 & 3.91 & 3.61 & 17.79 & 115.05 & 297.18 & 7.37 \\
\hline & SS & 6.26 & 0.34 & 5.64 & 3.33 & 3.32 & 0.85 & 0.84 & 3.96 & 18.18 & 92.45 & 0.72 \\
\hline & Chi-square & 2.02 & 4.69 & 5.67 & 7.90 & 10.80 & 8.13 & 8.07 & 5.04 & 1.14 & 4.17 & 0.14 \\
\hline & sd & 2 & 2 & 2 & 2 & 2 & 2 & 2 & 2 & 2 & 2 & 2 \\
\hline & $\mathrm{P}$ & 0.36 & 0.10 & 0.04 & 0.02 & 0.01 & 0.02 & 0.02 & 0.08 & 0.57 & 0.12 & 0.93 \\
\hline \multicolumn{13}{|c|}{10 YEAR AGE GROUP } \\
\hline \multirow{2}{*}{ Early(6) } & $\mathrm{X}$ mean & 18.50 & 4.48 & 37.33 & 24.00 & 22.00 & 5.33 & 5.00 & 18.82 & 134.33 & 410.00 & 6.68 \\
\hline & SS & 1.32 & 0.16 & 4.62 & 7.94 & 7.00 & 1.16 & 1.73 & 5.94 & 31.57 & 229.13 & 0.91 \\
\hline \multirow{2}{*}{ Medium (35) } & $\mathrm{X}$ mean & 20.83 & 4.33 & 40.28 & 15.39 & 14.93 & 4.93 & 4.70 & 19.74 & 127.70 & 381.33 & 6.83 \\
\hline & SS & 6.85 & 0.29 & 8.29 & 3.22 & 3.31 & 0.93 & 1.07 & 3.78 & 18.47 & 88.08 & 0.84 \\
\hline \multirow{2}{*}{ Late (16) } & $\mathrm{X}$ mean & 19.82 & 4.22 & 39.67 & 12.40 & 12.22 & 4.27 & 3.93 & 18.28 & 124.40 & 320.00 & 7.17 \\
\hline & SS & 5.16 & 0.17 & 3.85 & 2.36 & 3.54 & 0.80 & 1.10 & 3.46 & 17.78 & 82.46 & 1.05 \\
\hline \multirow{5}{*}{ Total(57) } & $\mathrm{X}$ mean & 20.48 & 4.31 & 40.00 & 15.09 & 14.63 & 4.80 & 4.53 & 19.35 & 127.23 & 368.30 & 6.90 \\
\hline & SS & 6.31 & 0.27 & 7.31 & 4.02 & 4.03 & 0.95 & 1.14 & 3.79 & 18.71 & 97.37 & 0.89 \\
\hline & Chi-square & 0.61 & 3.39 & 1.22 & 13.72 & 8.73 & 7.01 & 5.40 & 1.60 & 0.82 & 4.32 & 0.47 \\
\hline & $\mathrm{sd}$ & 2 & 2 & 2 & 2 & 2 & 2 & 2 & 2 & 2 & 2 & 2 \\
\hline & $\mathrm{P}$ & 0.74 & 0.18 & 0.54 & 0.00 & 0.01 & 0.03 & 0.05 & 0.45 & 0.66 & 0.12 & 0.79 \\
\hline \multicolumn{13}{|c|}{11 YEAR AGE GROUP } \\
\hline \multirow{2}{*}{ Early(6) } & $\mathrm{X}$ mean & 27.67 & 4.22 & 37.29 & 19.14 & 18.43 & 6.00 & 5.57 & 19.59 & 126.00 & 411.71 & 7.05 \\
\hline & SS & 4.00 & 0.36 & 8.50 & 2.54 & 2.94 & 1.29 & 0.79 & 3.83 & 15.92 & 12.47 & 0.60 \\
\hline Medium (35) & $\mathrm{X}$ mean & 22.45 & 4.26 & 44.17 & 18.39 & 17.09 & 5.15 & 4.91 & 19.42 & 130.08 & 435.12 & 6.75 \\
\hline
\end{tabular}




\begin{tabular}{|c|c|c|c|c|c|c|c|c|c|c|c|c|}
\hline & SS & 7.41 & 0.35 & 10.73 & 3.60 & 3.40 & 1.01 & 1.14 & 3.85 & 21.90 & 106.07 & 0.55 \\
\hline \multirow{2}{*}{ Late (16) } & $\mathrm{X}$ mean & 19.33 & 4.54 & 44.67 & 13.32 & 13.10 & 4.07 & 4.04 & 18.91 & 122.04 & 326.74 & 7.13 \\
\hline & SS & 6.59 & 0.56 & 4.80 & 2.90 & 3.27 & 1.17 & 0.94 & 3.32 & 16.10 & 78.27 & 0.72 \\
\hline \multirow{5}{*}{ Total(57) } & $\mathrm{X}$ mean & 22.03 & 4.32 & 43.86 & 17.21 & 16.21 & 4.95 & 4.74 & 19.31 & 127.88 & 407.53 & 6.86 \\
\hline & SS & 7.28 & 0.42 & 9.60 & 4.03 & 3.77 & 1.18 & 1.15 & 3.70 & 20.47 & 106.64 & 0.62 \\
\hline & Chi-square & 9.47 & 6.93 & 4.16 & 33.99 & 24.46 & 30.40 & 16.83 & 0.35 & 4.53 & 23.51 & 7.77 \\
\hline & $\mathrm{sd}$ & 2 & 2 & 2 & 2 & 2 & 2 & 2 & 2 & 2 & 2 & 2 \\
\hline & $\mathrm{P}$ & 0.01 & 0.03 & 0.13 & 0.00 & 0.00 & 0.00 & 0.00 & 0.84 & 0.10 & 0.00 & 0.02 \\
\hline \multicolumn{13}{|c|}{12 YEAR AGE GROUP } \\
\hline \multirow{2}{*}{ Early(6) } & $\mathrm{X}$ mean & 23.38 & 4.57 & 46.63 & 23.88 & 22.88 & 5.75 & 6.50 & 18.87 & 129.88 & 502.25 & 6.75 \\
\hline & SS & 6.92 & 0.90 & 17.89 & 4.49 & 4.64 & 1.49 & 1.41 & 4.27 & 24.71 & 54.82 & 0.55 \\
\hline \multirow{2}{*}{ Medium (35) } & $\mathrm{X}$ mean & 22.83 & 4.16 & 46.36 & 19.61 & 18.70 & 5.47 & 5.36 & 21.15 & 140.62 & 473.56 & 6.63 \\
\hline & SS & 7.74 & 0.59 & 14.39 & 3.90 & 4.00 & 1.20 & 1.45 & 4.51 & 21.83 & 92.52 & 0.68 \\
\hline \multirow{2}{*}{ Late (16) } & $\mathrm{X}$ mean & 19.16 & 4.22 & 45.36 & 16.45 & 15.65 & 4.71 & 4.46 & 21.29 & 135.61 & 412.75 & 6.61 \\
\hline & SS & 8.16 & 0.34 & 8.44 & 5.97 & 5.62 & 1.41 & 1.04 & 4.37 & 24.39 & 113.96 & 0.37 \\
\hline \multirow{5}{*}{ Total(57) } & $\mathrm{X}$ mean & 22.03 & 4.20 & 46.15 & 19.17 & 18.28 & 5.32 & 5.23 & 21.04 & 138.78 & 461.59 & 6.63 \\
\hline & SS & 7.89 & 0.57 & 13.43 & 4.80 & 4.75 & 1.30 & 1.44 & 4.46 & 22.64 & 99.19 & 0.61 \\
\hline & Chi-square & 4.82 & 7.25 & 0.56 & 22.10 & 16.32 & 8.85 & 17.70 & 1.82 & 4.04 & 7.89 & 0.10 \\
\hline & $\mathrm{sd}$ & 2 & 2 & 2 & 2 & 2 & 2 & 2 & 2 & 2 & 2 & 2 \\
\hline & $\mathrm{P}$ & 0.09 & 0.03 & 0.76 & 0.00 & 0.00 & 0.01 & 0.00 & 0.40 & 0.13 & 0.02 & 0.95 \\
\hline \multicolumn{13}{|c|}{13 YEAR AGE GROUP } \\
\hline \multirow{2}{*}{ Early(6) } & $\mathrm{X}$ mean & 25.78 & 4.14 & 56.17 & 38.83 & 35.00 & 8.67 & 8.50 & 26.35 & 157.17 & 544.67 & 6.02 \\
\hline & SS & 5.89 & 0.84 & 15.94 & 7.31 & 6.57 & 1.97 & 2.43 & 4.88 & 20.34 & 98.64 & 0.43 \\
\hline \multirow{2}{*}{ Medium (35) } & $\mathrm{X}$ mean & 21.93 & 3.93 & 52.15 & 24.49 & 23.13 & 6.21 & 6.07 & 22.91 & 148.90 & 437.30 & 6.38 \\
\hline & SS & 7.33 & 0.30 & 7.84 & 5.35 & 5.10 & 1.51 & 1.55 & 4.11 & 21.75 & 82.97 & 0.51 \\
\hline \multirow{2}{*}{ Late (16) } & $\mathrm{X}$ mean & 20.31 & 4.05 & 50.86 & 20.31 & 19.55 & 5.75 & 5.39 & 22.27 & 143.25 & 348.75 & 6.56 \\
\hline & SS & 8.20 & 0.26 & 11.52 & 5.72 & 5.93 & 1.08 & 1.13 & 4.25 & 20.52 & 82.83 & 0.48 \\
\hline \multirow{4}{*}{ Total(57) } & $\mathrm{X}$ mean & 21.70 & 3.98 & 52.02 & 24.16 & 22.83 & 6.23 & 6.02 & 22.94 & 147.76 & 417.98 & 6.41 \\
\hline & SS & 7.56 & 0.35 & 9.61 & 6.98 & 6.46 & 1.56 & 1.65 & 4.26 & 21.39 & 97.86 & 0.51 \\
\hline & Chi-square & 2.37 & 5.79 & 3.82 & 26.24 & 23.79 & 10.58 & 10.03 & 3.93 & 2.32 & 31.12 & 5.95 \\
\hline & $\mathrm{sd}$ & 2 & 2 & 2 & 2 & 2 & 2 & 2 & 2 & 2 & 2 & 2 \\
\hline
\end{tabular}




\begin{tabular}{|c|c|c|c|c|c|c|c|c|c|c|c|c|}
\hline & $\mathrm{P}$ & 0.31 & 0.04 & 0.15 & 0.00 & 0.00 & 0.01 & 0.01 & 0.14 & 0.31 & 0.00 & 0.04 \\
\hline \multicolumn{13}{|c|}{14 YEAR AGE GROUP } \\
\hline \multirow{2}{*}{ Early(6) } & $\mathrm{X}$ mean & 20.30 & 3.81 & 66.70 & 30.96 & 27.60 & 7.20 & 7.00 & 25.29 & 161.00 & 502.50 & 6.24 \\
\hline & SS & 6.26 & 0.54 & 12.87 & 7.87 & 6.47 & 2.53 & 2.16 & 5.77 & 17.34 & 143.40 & 0.55 \\
\hline \multirow{2}{*}{ Medium (35) } & $\mathrm{X}$ mean & 21.40 & 3.88 & 59.07 & 28.19 & 28.05 & 7.19 & 6.57 & 23.66 & 155.02 & 475.83 & 6.45 \\
\hline & SS & 7.19 & 0.48 & 15.13 & 6.37 & 6.37 & 1.45 & 1.67 & 4.62 & 19.27 & 97.86 & 0.63 \\
\hline \multirow{2}{*}{ Late (16) } & $\mathrm{X}$ mean & 22.63 & 4.04 & 62.21 & 21.00 & 20.74 & 5.21 & 4.95 & 23.09 & 143.74 & 393.16 & 6.33 \\
\hline & SS & 5.49 & 0.66 & 6.55 & 4.31 & 4.33 & 0.92 & 0.97 & 3.25 & 19.24 & 96.32 & 0.55 \\
\hline \multirow{5}{*}{ Total(57) } & $\mathrm{X}$ mean & 21.58 & 3.91 & 60.99 & 26.66 & 26.03 & 6.66 & 6.20 & 23.73 & 152.85 & 457.46 & 6.39 \\
\hline & SS & 6.60 & 0.54 & 13.18 & 7.02 & 6.66 & 1.75 & 1.75 & 4.47 & 19.65 & 110.69 & 0.60 \\
\hline & Chi-square & 1.47 & 2.11 & 2.38 & 21.65 & 18.83 & 21.39 & 15.52 & 0.91 & 5.99 & 10.49 & 0.84 \\
\hline & sd & 2 & 2 & 2 & 2 & 2 & 2 & 2 & 2 & 2 & 2 & 2 \\
\hline & $\mathrm{P}$ & 0.48 & 0.35 & 0.30 & 0.00 & 0.00 & 0.00 & 0.00 & 0.63 & 0.05 & 0.01 & 0.66 \\
\hline
\end{tabular}


The 20 meter shuttle run and finger and hand grip strength variables in the 9 year age group, hand and finger grip strength variables in the 10 year age group, flexibility, 20 meter speed run, hand and finger grip strength, med ball throw and pro-agility variables in the 11 year age group, 20 meter speed run, hand and finger grip strength and med ball throw variables in the 12 year age group, 20 meter speed run, hand and finger grip strength, med ball throw and pro-agility variables in the 13 year age group and hand and finger grip strength, standing long jump and med ball throw variables in the 14 year age group showed differences in terms of the maturity coefficient. Maturity was found to be not effective in terms of other parameters. In the light of these findings, the maturity level is observed to be effective over the bio motoric parameters among the parameters that show differences based on the biological maturity.

\section{Discussion and Results}

When the flexibility variable was examined, the early developing children from the 9, 10,11 and 12 year age group showed higher levels of flexibility in terms of biological maturity when compared to the normal developing children, while on the other hand the normal developing children from the same age group showed higher levels of flexibility in comparison with the late developing children. Certain anatomical and functional structure features the joints have may affect the flexibility.

According to Pratt [13], the flexibility levels of the males are stable between the ages of 5-8, while a decrease is observed in the flexibility levels when the children reach 11-12-13 years of age, the flexibility is stable between the ages of 13-15 and increases until 18 years of age. This situation indicates that among the male children of the 11-12 year age group, which is when the biological development differences begin to show and the flexibility begins to decrease on a numeral manner, the early developing children when compared to normal developing children and the normal developing children in comparison with late developing children live the flexibility development with priority and enter biological maturity in this respective order.

Similar to the study findings; while Gül and Seyrek [14] in the study they conducted with 84 male children in the 10-12 year age group and who do not perform sports activities, determined the mean value for flexibility to be $10,7 \pm 3,6 \mathrm{~cm}$; they identified the minimum value to be $2 \mathrm{~cm}$. and the maximum value as $20 \mathrm{~cm}$.

When the speed variable was analyzed, the only significant difference was observed in the 11,12 and 13 year age group. In the 12 and 13 year age group in terms of biological maturity, the early developing children were observed to be advantageous in comparison with late developing children while late developing children were noted to be advantageous when compared to normal developing children. However in the male children in the 11 year age group, in terms of biological maturity, the late developing children were observed to have better speed performances when compared to normal developing children while normal developing children had better performances in comparison with early developing children.

According to Mengütay [1], growth and development speeds progress rapidly in the 8-11 and 11-13 age periods. In the period the students are in, an increment also occurs in their movement speeds. The speed performances of the children reach their peak levels at the age of 10 . The reaction speed develops in periods that follow.

When the shuttle run (aerobic capacity) variable was examined, no significant difference could be found in male children in terms of biological maturity.

When the Right Hand grip strength was analyzed for the male children in the $9,10,11,12,13$ and 14 year age group and in terms of biological maturity, the early developing children showed significant differences when compared to normal developing children while normal developing children showed significant differences in comparison with late developing children.

In the study of Gül et al., [14] named "Comparison of Certain Anthropometric Features between Male Children Who do and Who do Not Attend the 10-12 Year Basic Athletics Sports Education Course" which involved 84 male children, the researchers identified the right hand grip strength mean value as $15,7 \pm 3,1 \mathrm{~kg}$.; the minimum value as $7,9 \mathrm{~kg}$., and the maximum value as $23,6 \mathrm{~kg}$.

Upon the examination of the Left Hand grip strength for the male children in the $9,10,11,12,13$ and 14 year age group in terms of biological maturity, the early developing children were found to show significant differences when compared to normal developing children while normal developing children significantly differed from the late developing children. In the 14 year age group however, normal developing children were found to be advantageous in terms of biological maturity when compared to early developing children while early developing children were found to be advantageous in comparison with late developing children.

According to Demirel [15], the grip strength develops along with age. This is an indicator of early developing children being advantageous. In the results we reached in parallel with other conducted studies, in terms of biological development in correlation with their physical development, early developing children were found to be advantageous in comparison with normal developing children and normal developing children were observed to be advantageous when compared to late developing children. Results indicate that early development is important for hand grip strength in terms of biological maturity especially in these ages.

Gül et al. [14] in their study which they conducted with 84 male children in the 10-12 year age group and who did not perform any sports activities found the left hand grip strength mean value as $15,3 \pm 2,8 \mathrm{~kg}$.; the minimum value as $9 \mathrm{~kg}$. and the maximum value as $23,5 \mathrm{~kg}$. The results of the study 
showed parallelism with the results of this study.

In the Right Finger grip strength variable for the children in the $9,10,11,12,13$ and 14 year age group, children who were early developers showed significant differences in comparison with normal developing children while normal developing children were observed to display significant differences when compared to late developing children.

According to Cüceloğlu [16], in terms of small muscle groups, development starts in children at the age of 6 and continues the process of development incrementally at the age of 9 and later. This incrementally continuing skill increase can be stated as the reason for the early developing children being advantageous when compared to normal developing children and on the other hand, normal developing children have an advantage over late developing children.

A significant difference was observed in the Left Finger grip strength variable in terms of the biological maturity levels of the children in the $9,10,11,12,13$ and 14 year age group. The left finger strength values of the early developing children were higher when compared to the values of normal developing children and the values of normal developing children were higher in comparison with the values of late developing children.

According to Cüceloğlu [16]; the development of the left finger strength -similar to the development of the right finger strength- is increased through the ages of 6-10 and allows the children to enter a period in which they will be able to use their fingers more effectively. The early developing children enter this period earlier than the normal developing children and become advantageous in terms of biological maturity while the same advantage is on the side of normal developing children when compared to the late developing children.

The med ball throw variable showed significant differences in terms of the biological maturity only in the 11, 12,13 and 14 year age groups. The early developing children were advantageous when compared to late developing children.

In the study conducted by Pekel et al [17], med ball throw was used in the measurement of the arm strength. On the other hand, this test was identified to be also usable as a muscle strength and endurance test. The increase in the level of strength in children aged from 6 to 12, -during which, the development of strength is rapid- is not connected only with the lever system becoming suitable. Hormonal development, the central nerve system becoming functional and fit for the purpose, being able to endure the $\mathrm{O} 2$ debt also share an important effect on the strength development in this period. Therefore, maximal power, quick power and continuity in power show differences depending on age.

Gül and Seyrek [14] in their study where they worked with 84 male children who did not perform sports activities, found the mean value for standing med ball throw as $507,5 \pm 0,92$ $\mathrm{cm}$., the minimum value as $313 \mathrm{~cm}$ and the maximum value as $715 \mathrm{~cm}$.

In the light of this information it can be stated that in the
12-13-14 year age groups, the biological maturity development in male children forms significant differences in the expected direction. Biological development begins early in the male children who catch the early development. The normal developing male children come up later in the list of development while the late developing male children are in the last place. Due to the fact that the male children in the 11 year age group are in the primordium of the strength development, the normal developing children are considered to be advantageous in terms of biological maturity.

When the standing long jump variable was examined, only in the 14 year age group the early developing children seemed to be advantageous when compared to normal developing children while the normal developing children were advantageous in comparison with the late developing children.

In their studies, Sevimay [18] and Dursun [19] identified the sitting long jump performance of the children to be linearly increasing in accordance with the age.

When the agility variable was examined, significant differences were only visible in the 11 and 13 year age groups. In the male children of the 11 year age group the normal developing children appeared to be advantageous when compared to early developing children in terms of biological maturity while the early developing children shared the same advantage against the late developing children. In the male children of the 13 year age group however the early developing children appeared to be advantageous when compared to the normal developing children while the same advantage was on the side of the normal developing children when compared to the late developing children.

According to Gallahue [20], the motor skills are gained and developed, depending on the development of the nervous system. Normal developing children gain the motor skills at the expected age. Balance, power, agility and endurance which increase with age, are factors which are effective in gaining these skills.

Agility is in close relation with balance and coordination. Children can face skill problems at this age (11) due to quickly developing organelles and normal children may be advantageous; however -as it is stated in the literaturefollowing the coordinative rapport of the organelles which undergo a fast change depending on age (13), due to the fact that this advantage disappears, the early developing children become advantageous.

In the male children of the 13 year age group, the early developing children appeared to be advantageous when compared to the normal developing children while the normal developing children were advantageous in comparison with the late developing children. The reasoning behind this situation however can be the fact that the advantage shows differences due to the differences in development, increase in body height, and with priority, passing into the period where motoric features are developed. 
Upon the examination of the Countermovement Jump variable, no significant differences in terms of biological maturity were found $(\mathrm{p}>0,05)$.

Considering the children to be talented in the sportive sense only based on the physical and physiological structure along with the motoric features is not seen as an efficient method in today's world. Now, the factors which affect the development and talents of the children are known to be multi-disciplinary. Studies which ignore the biological maturity and psycho-social states of the children are problematic in reliability and validity.

The growth process should be taken into consideration while evaluating the physical performance of children and adolescents [21]. The results of the study are overlapping with this logic. Not only evaluating the children based on their chronological ages during the talent selection process but also taking into consideration the differences of their biological developments has importance from the point of decoding the results reliably.

The motor development levels and motor performance features they display have an important place in the sportsmen talent selections. However the biological maturity levels of the children are not always taken into consideration during the talent tests applied to the children. This case prevents the reliable evaluation of the data collected from the talent selection. Especially in the tests applied to the children from the same age group, ignoring the biological maturity levels of the children causes the children with good performances to be considered as talented while children who perform poorly are considered to have low levels of talent. Not determining the biological maturity levels of the children and not considering whether the children are part of early or late development, prevents true interpretation of the talent test results.

The information within the literature and the results of this study indicate that the biological maturity is a matter to take into consideration in the talent selection in sports. At this point both the local sports organizations and the sport ministry need to turn to applications which will take the biological maturity levels of the children into consideration. Similarly the trainers who aim to find the talented sportsmen within their field of interest considering the biological and chronological ages of the children in addition to the talent tests will be beneficial in identifying the true talents.

\section{REFERENCES}

[1] Mengütay, S. (2005). Sports and Movement Development for Children. İstanbul: Morpa Culture Publications.

[2] Demirci, A. (2006). Physical Education Applications in Primary Schools. İstanbul: Değişim Publications.

[3] Özer, DS., Özer, MK. (2001). Motor Skills Development in Children. 2nd Edition. Ankara: Nobel Publications.
[4] Malkoç, İ. (2006). Shortness of Height. Van Medical Journal, 13(2), 67-70.

[5] Kayapınar F. Ç. (2007). Researching the Sample Pilot Study Program's Effects on the Anthropometric, Posture, and Physical Suitability Levels of the Pre-School Children, Marmara University Institute of Medical Sciences, Unpublished Doctoral Thesis, İstanbul.

[6] Özalp İ, Coşkun T. (1995). Observation of Growth. Tunçbilek E (ed). Children's Health Fundamental Information. Ankara.

[7] Işık, T. (2007). Evaluation of the Socio-Economical Status, Anthropometric Body Measurements, Growth and Development with Menarch of Female Students in Konya within the Age Group of 11-16. S.D.Ü. Medical Faculty Journal. 14(1), 25-28.

[8] Acun, S., Erten, G.B. (1999). Child Development. İstanbul: Esin Publications.

[9] İnce, T; Kondolot, M; Yalçın, S. (2011). Growth Observation and Growth Halt. Turey Child Illnesses Journal, 5(3): 181-192.

[10] Bektaş, Y. (2010). The Effects of Genetics and Environment on the Anthropometric Features, Unpublished Doctoral Thesis, Ankara University Social Sciences Institution, Ankara.

[11] Sayın, M. (2011). Movement and Skills Teaching. İzmir: Spor Publications \& Library.

[12] Çankaya, C., Arabacı, R., Doğan, M., Kılıç, C. (2004). Wrestling Training Center in Bursa and Talent Selection in the Active Wrestling Clubs. Physical Education and Sports Sciences Journal, 6(1), 11-17.

[13] Pratt M. (1989). Strength, Flexibility, and Maturity in Adolescent Athletes. Am J Dis Child. 143,560 563. Taken from

Internet:http://www.atletik.org/CucuklardaDayaniklilikGelis imi.htm in December, 2014.

[14] Gül, G.K., Seyrek, E., Sugurtin, M. (2006). Comparison of Certain Anthropometric Features between Male Children Receiving and not Receiving Basic Athletism Sports Educastion in the 10-12 Age Group. 9th International Sports Sciences Congress, 3-5 December, Muğla University, Muğla.

[15] Demirel, P. (2005). Comparison of Hand Anthropometric Measurements and Hand Grasp Strength in Different Sports Branches, Unpublished Doctoral Thesis, Zonguldak Karaelmas University Institute of Medical Sciences, Zonguldak.

[16] Cüceloğlu, D. (2000). Human and Behavior. 10th Edition, Remzi Publications. İstanbul.

[17] Pekel, H.A., Bağcı, E., Güzel, N.A., Onay, M., Balcı, S., Pepe, H. (2006) Evaluation of the Relationship between the Anthropometric Features and Physical Fitness Test Results related to the Performance, in Children who perform Sports Activities. Kastamonu University Kastamonu Education Journal, 14(1), 299-308.

[18] Sevimay, D. (1986) Examining the Motor Skill Performances of Children in the Pre-School Period. Scientist Expertise Test, Hacettepe University Institute of Medical Sciences, Ankara. 
[19] Dursun, M. Z. (2003) The Effect of the Special Physical Education Program Proposal including the Basic Motor Skills on the Pre-School 6 year old Children's Motor Skill Levels, Scientist Expertise Test, Hacettepe University Institute of Medical Sciences, Ankara.
[20] Gallahue, D.L. (1982) Understanding Motor Development in Children, Boston, MA; John Wiley\&Sons, Inc.

[21] Sağlam F, Rakıcıoğlu N.,Karaağaoğlu N., Hazır T., Cinemre A., Tınazcı C., Agçı A., 